\title{
THERMAL AND ELECTRICAL ANALYSIS OF SOLID ALUMINIUM CAPACITORS
}

\author{
E.H.L.J. DEKKER and C.J.M. LASANCE \\ Philips Elcoma, Zwolle, and Philips Centre for Technology, Eindhoven, Netherlands \\ (Received November 28, 1985; in final form February 27, 1986)
}

\begin{abstract}
The thermal properties of electronic components partly determine the reliability of electronic equipment. For electrolytic capacitors, they also set the limits for the ripple current and voltage values.

This article first discusses the voltage limits under various conditions of temperature, frequency and polarity. Then the connection of ripple current to these parameters and to the capacitor's resistance is treated.

An extensive analysis is made of the influence of heat conduction in the capacitor and the printedcircuit board, for metal-cased as well as for epoxy-coated pearl types. The study pays particular attention to solid aluminium capacitors containing a manganese dioxide semiconductor. They have some extraordinary properties: a temperature range of at least -80 to $+175^{\circ} \mathrm{C}$, and an appreciable reverse voltage potential.These can be fully employed to improve the ripple-current specification.
\end{abstract}

Keywords: Capacitors; solid aluminium; ripple current; thermal analysis; heat transfer.

\section{INTRODUCTION}

Electrolytic capacitors are most widely used because of the high capacitance they offer. Their application implies several boundary conditions which this paper discusses, in particular with respect to temperature and to positive, negative and alternating voltages and currents. The combination of these factors leads to a specification of ripple current and ripple voltage. The resultant specification is also dependant on the physical model that describes the heat transfer from the interior of the capacitor to the surroundings.

The influences of the physical properties and the thermal model on the specifications are relevant to all small electrolytic capacitors, in particular to epoxy lacquer coated pearl types having radial leads, and to those metal-cased axialleaded types having case sizes up to $15 \mathrm{~mm}$ in diameter and $40 \mathrm{~mm}$ in length. We will be concentrating here on solid aluminium capacitors because they can be used in extremes of temperature and with high alternating voltages. Extreme environments occur in few applications where the capacitor can be the critical element. ${ }^{1}$ In regular industrial designs, these capacitors permit a more extended ripple-current specification. Furthermore, the trend in size reduction typical for electronic components in general is also manifest for these capacitors, ${ }^{2}$ which necessitates an investigation on their ripple-current specification.

\section{CAPACITOR PROPERTIES}

\subsection{Capacitor Construction}

In most electrolytic capacitors the anode is a porous metal construction (sintered powder or etched foil or plate). The dielectric oxide is obtained by anodisation of the porous body. The cathode is an electrolyte fluid having ionic conduction in the 
case of wet electrolytic capacitors, sometimes called "dry" capacitors because of the gellified solvent-type electrolyte. Solid electrolytic capacitors have a semiconducting manganese dioxide cathode. Some types use an organic semiconductor, based on a TCNQ-salt. The outside connection to the cathode is made by a contact metal construction, In wound-metal foil capacitors a second foil is applied, separated from the anode foil by a paper or glass-fabric spacer. This foil carries an only thin dielectric oxide layer, obtained by thermal or electrochemical means. In folded-plate or sintered slug capacitors a series of contact layers is applied: graphite, silver, soldering. The capacitor body is finally coated with a polymer coating or put into a case. The body may make contact with the case; or may be at a certain distance from the case, seperated by air or by a polymer filling. Figure 1 shows the constructions.

\subsection{Temperature Limitation}

Capacitor temperatures are limited by the stability of materials and individual properties, but also indirectly by the connections between the various parameters. The important relations are:

$$
\begin{aligned}
& \mathrm{V}=\mathrm{i} \cdot \mathrm{Z} \\
& \mathrm{Z}=\mathrm{R}+\mathrm{j}(2 \pi \mathrm{fL}-1 /(2 \pi \mathrm{fC})) \\
& \mathrm{Q}=\mathrm{i}^{2} \mathrm{R},
\end{aligned}
$$

in which $\mathrm{V}$ is the ripple voltage, $\mathrm{i}$ the ripple current, $\mathrm{Z}$ the impedance, $\mathrm{R}$ the equivalent series resistance, $\mathrm{L}$ the equivalent series inductance, $\mathrm{f}$ the ripple frequency, $\mathrm{C}$ the capacitance, and $\mathrm{Q}$ the heat dissipation. At frequencies below $10 \mathrm{kHz}$ the $2 \pi \mathrm{fL}$ term in $\mathrm{Z}$ can be neglected. Below $50 \mathrm{~Hz}$, the use of an equivalent series resistance term $R$ becomes less appropriate. This term is first composed of the real series resistance contributions by the contact electrode and the cathode (in the anode pore structure and around the body). Second, the dielectric oxide

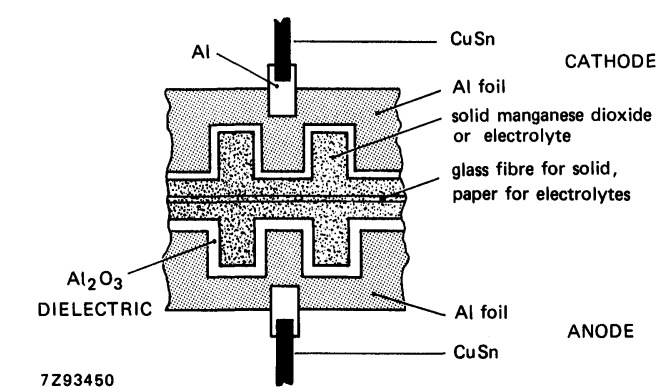

FIGURE 1 a - Structure of solid and wet electrolytic capacitors using a wound-foil construction

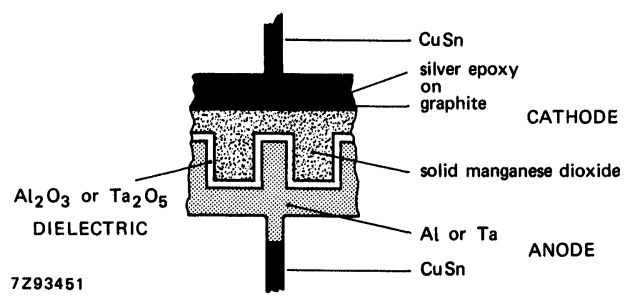

FIGURE 1 b - Structure of solid capacitors using a folded plate or sintered slug construction 
presents a real series resistance contribution, but also a parallel resistance which accounts for the leakage current. The translation of the latter into a series resistance causes this to increase with decreasing frequency stronger than the other contributions. For the heat dissipation, Q, the contribution by the leakage current in the parallel resistance can normally be neglected. It can certainly not be replaced by the heat dissipation of the ripple current, $i$, in the part of the equivalent series resistance resulting from the translated parallel resistance.

The low temperature boundary of a capacitor is primarily determined by the increase of the cathode resistance and the accompanying loss of capacitance at a given frequency. Because of the better temperature coefficient of the resistance of manganese dioxide compared to electrolytic fluids, the low temperature boundary can be specified lower for solid than for wet electrolytic capacitors. Figure 2 shows a typical picture of capacitance variation with temperature. Secondarily, for wet capacitors, the impedance $(\mathrm{Z})$ increases strongly at low temperatures (factor of 10 referring to $25^{\circ} \mathrm{C}$ ). For solid capacitors, this occurs only to some extent (factor of 2) in the 0.1 to $1 \mathrm{MHz}$ range because there the inductance and capacitance terms neutralize each other and impedance becomes approximately equal to resistance.

The high temperature boundary of a capacitor is primarily determined by the stability of the cathode and the dielectric. Wet electrolytic capacitors suffer from a loss of electrolyte through evaporation, causing an increase of resistance and loss

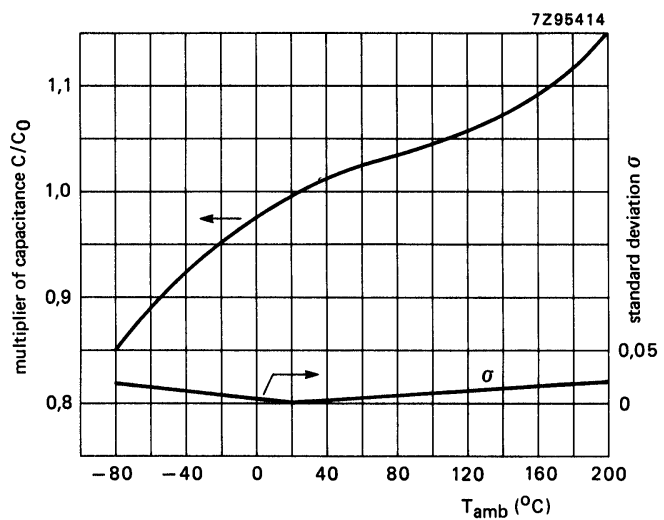

FIGURE 2 a - Multiplier of capacitance as a function of ambient temperature, for solid aluminium capacitors

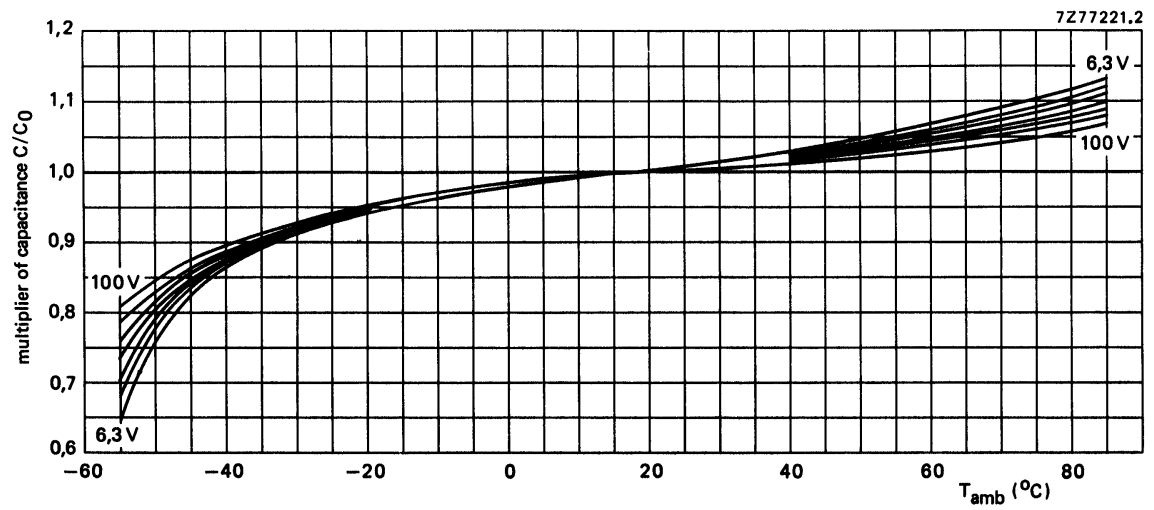

FIGURE 2 b - Same, for wet aluminium capacitors in the same capacitance range 
of capacitance. This process is strongly temperature and time dependent, leading to life expectancies of a few thousand hours at temperatures between 85 and $125^{\circ} \mathrm{C}$. The stability of manganese dioxide allows for temperatures up to about $300^{\circ} \mathrm{C}$ in solid aluminium capacitors. A soldered cathode connection may cause a lower temperature limit, e.g. $175^{\circ} \mathrm{C}$. Regular life expectancies range from more than $1000000 \mathrm{~h}$ at $125^{\circ} \mathrm{C}$ to more than $5000 \mathrm{~h}$ at $175^{\circ} \mathrm{C}^{3}$ The solid organic TCNQ-salt develops above $85^{\circ} \mathrm{C}$ into a non-conducting variant before melting at $260^{\circ} \mathrm{C}$.

The stability of the dielectric is reflected in its breakdown characteristics and to a small extent in its leakage current. Leakage current increases at least exponentially with temperature. In wet capacitors, this leads to accelerated consumption of the electrolyte and shorter lifetime. Voltage derating lowers leakage current exponentially. It also prevents dielectric breakdown. Derating starts at $85^{\circ} \mathrm{C}$ or $125^{\circ} \mathrm{C}$ and ends at 125 or $200^{\circ} \mathrm{C}$, according to manufacturers' present specifications for solid tantalum and solid aluminium capacitors, respectively.

Secondarily, the application of a ripple current will heat the capacitor core beyond ambient temperature. Furthermore the impedance decreases at high temperatures, so the application of a ripple voltage without limiting the current can cause excessive currents. The impedance decrease is due to the resistance decrease and capacitance increase. The resistance decreases at increasing temperature until the cathode contribution is overruled by the dielectric oxide influence. The temperature where the resistance stabilizes decreases with increasing capacitor sizes. Figure 3 compares two different types of capacitors concerning this aspect.

The capacitor construction and position in the printed-circuit board determines the difference between core and ambient temperatures. The core temperature is generally allowed to be 10 to $20^{\circ} \mathrm{C}$ above maximum rated temperature. ${ }^{4-6}$

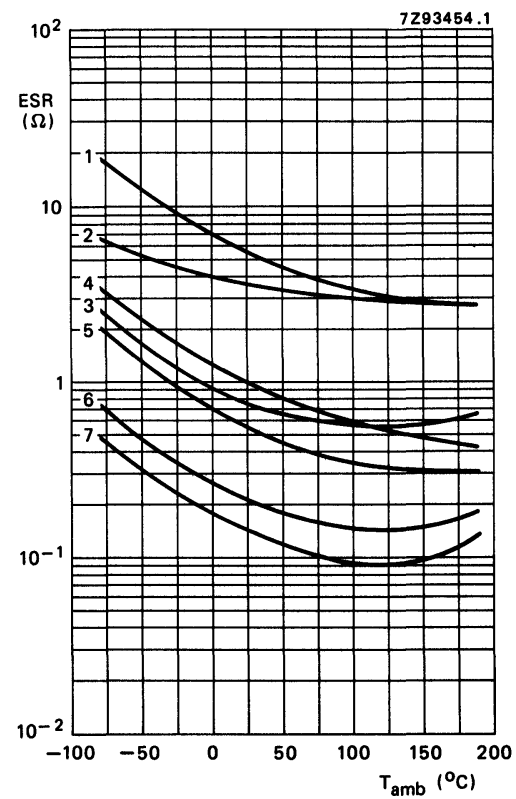

FIGURE 3 a - Equivalent Series Resistance as a function of ambient temperature at a frequency at $100 \mathrm{~Hz}$, for metal-case solid aluminium capacitors

$1=33 \mu \mathrm{F}-25 \mathrm{~V}$

$2=47 \mu \mathrm{F}-20 \mathrm{~V}$

$3=100 \mu \mathrm{F}-10 \mathrm{~V}$

$5=220 \mu \mathrm{F}-20 \mathrm{~V}$

$4=150 \mu \mathrm{F}-35 \mathrm{~V}$

$=330 \mu \mathrm{F}-10 \mathrm{~V}$

$7=1000 \mu \mathrm{F}-6,3 \mathrm{~V}$ 


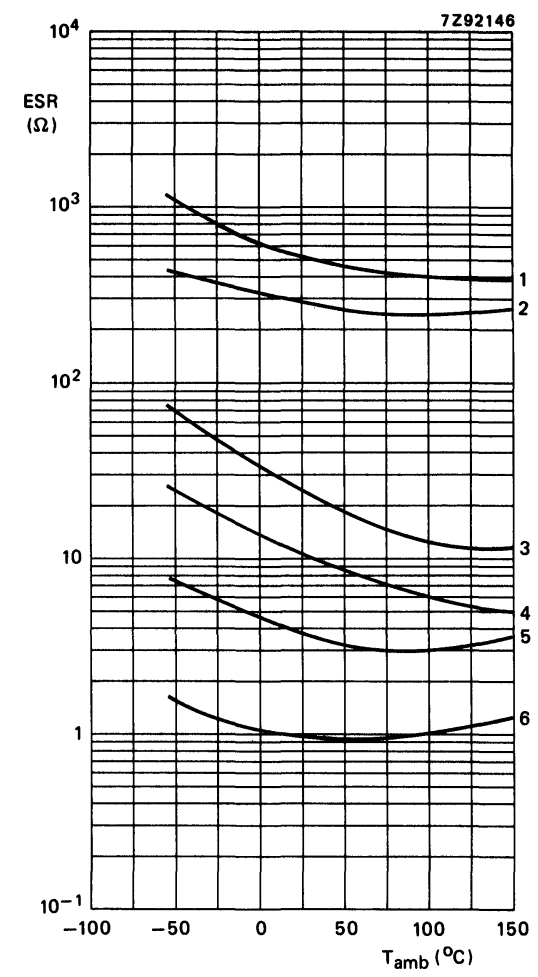

FIGURE 3 b - Typical ESR at $100 \mathrm{~Hz}$, as a function of ambient temperature for lacquered pearl solid aluminium capacitors

$1=0.1 \mu \mathrm{F}-40 \mathrm{~V}$

$2=1,5 \mu \mathrm{F}-40 \mathrm{~V}$

$3=3,3 \mu \mathrm{F}-25 \mathrm{~V}$

$$
\begin{aligned}
& 4=10 \mu \mathrm{F}-6,3 \mathrm{~V} \\
& 5=22 \mu \mathrm{F}-10 \mathrm{~V} \\
& 6=68 \mu \mathrm{F}-6,3 \mathrm{~V}
\end{aligned}
$$

\subsection{Voltage Limitation}

The working voltage in forward polarity must be kept below the anodisation voltage to avoid prolonged anodisation accompanied by heavy gas evolution (for wet capacitors) or dielectric breakdown (for wet capacitors if the sparking voltage of the electrolyte has been surpassed, and for solid capacitors). Normally, it will be lowered even further to obtain lower leakage current values and a better reliability. This voltage is specified by the manufacturer as the rated voltage. For short periods, the rated voltage can be surpassed to a higher limit specified as the surge voltage. The limit is 1,15 to 1,3 times the rated voltage for periods of several seconds. Short pulses of milli-seconds duration can be sustained up to several times the rated voltage, at least for aluminium capacitors. ${ }^{7}$ Tantalum capacitors must be used with a series resistance, particularly when dynamic loads are expected ${ }^{8}$ to avoid surge currents leading to dielectric breakdown by electric-field induced crystallisation of the tantalum pentoxide dielectric ${ }^{9}$ or possibly mechanical damage. ${ }^{10-11}$ No such failure mechanism is known for aluminium capacitors $^{12}$ which can be explained by the fact that both crystalline and amorphous aluminium oxide dielectric layers can be applied for these capacitors.

In reverse polarity, the negative charge to the dielectric layer is no longer generated through the interface with a semiconductor or electrolyte, but through 
the contact with the metal that in forward polarity constitutes the anode. The phenomena at this interface are not completely understood. One might suppose that electron injection now proceeds much faster, meaning the leakage current increases at a lower voltage ${ }^{13}$ level. In wet capacitors, the hardly oxidized metal foil that constitutes the contact to the electrolyte will now be anodised, again accompanied by heavy gas evolution at the other electrode. In solid capacitors, dielectric breakdown can occur. Limits set for voltage reversal are mostly 0,5 to $2 \mathrm{~V}$ for wet electrolytic and solid tantalum capacitors, for a brief duration. For solid aluminium capacitors the margins are wider: during d.c. voltage reversal at $125^{\circ} \mathrm{C}$ 15 to $30 \%$ of rated voltage can be tolerated continuously. Figure 4 shows an example of the asymmetry of their leakage current. The reverse voltage specification is chosen at a value where the leakage current reaches about the same level as in forward polarity at rated voltage.

Alternating or ripple voltages can in principle, provided no internal heating by ripple current occurs, be increased beyond the limits specified for d.c. voltage in the positive (forward) and negative (reversed) polarity. The limited mobility of the charge carriers in the dielectric layer prevents them from fully penetrating this layer if the voltage is reversed in time. The relaxation time for charge transfer is known to be approximately 10 seconds $^{14}$ if the real part of the current density is $0,003 \mathrm{~mA} / \mathrm{cm}^{2}$ relating to the anode's physical surface area. It follows that already at a frequency of $0,1 \mathrm{~Hz}$ a beneficial a.c. effect can be present. In solid aluminium capacitors this effect allows alternating voltage values up to $80 \%$ of rated voltage at zero d.c. voltage, ${ }^{15}$ see Table I. In wet capacitors, the gas evolution at the cathode limits the use of this effect to applications involving very small currents only.

By way of precaution only, the a.c. voltage in solid aluminium capacitors is limited to $2 \mathrm{~V}$ if a negative d.c. bias is applied, to avoid a possible excessive accumulation of charge carriers. A positive or zero bias allows the ripple voltage to take on any value between rated voltage (in the positive half-wave) and the limits of Table I (in the negative half-wave). The quantitative theorectical explanation of these voltage limits is still lacking. The data given before are based on results of tests showing no harmful effects.

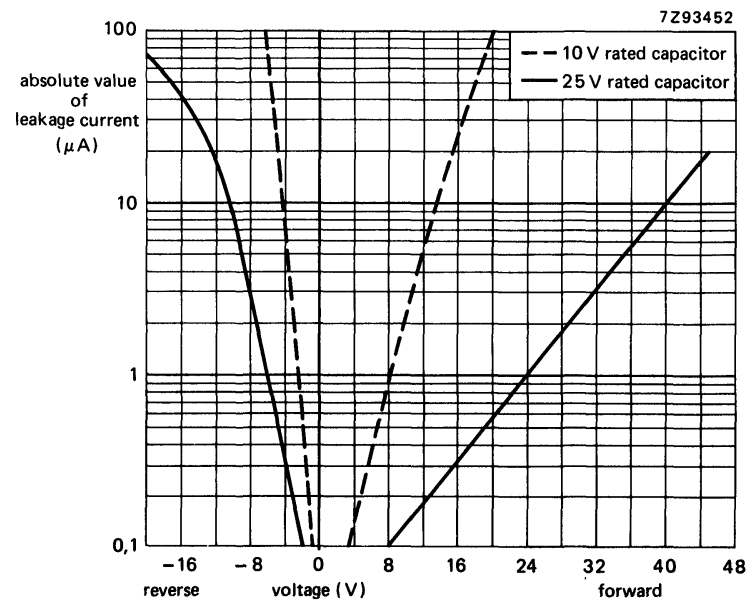

FIGURE 4 Leakage current as a function of voltage in forward or reverse polarity. Examples: solid aluminium axial capacitors, $100 \mu \mathrm{F}-10 \mathrm{~V}$ and $22 \mu \mathrm{F}-25 \mathrm{~V}$ ratings 
TABLE I

Ripple voltage multipliers for solid aluminium capacitors

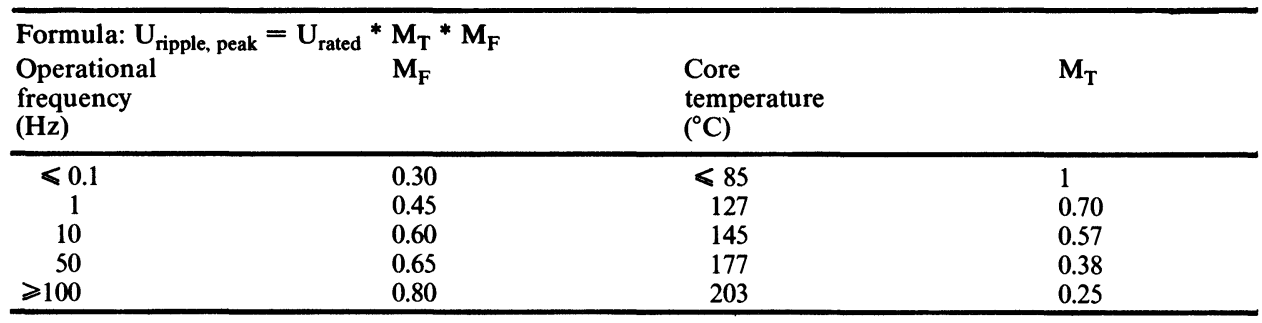

\subsection{Ripple Current Limitation}

The ripple current is limited by the allowable heat dissipation (through the capacitor's resistance) and by the ripple voltage (through the capacitor's impedance). The temperature influence on resistance and impedance has been discussed before. These parameters are also influenced by the ripple frequency. At increasing frequency the resistance decreases (by the telegraph-line effect, ${ }^{16}$ ). Between 10 and $100 \mathrm{~Hz}$ the resistance decreases by one order of magnitude. High ESR values at these low frequencies are often neglected because ESR is mostly specified at $100 \mathrm{~Hz}$. However, they can very badly affect the ripple performance of wet electrolytic capacitors. ${ }^{17}$ In the range of $100 \mathrm{~Hz}$ to $1 \mathrm{Mhz}$, the decrease is again approximately by one order of magnitude for solid aluminium capacitors, as Figure 5 demonstrates. For wet capacitors this decrease stops at about half the $100 \mathrm{~Hz}$ value of the ESR. The impedance decreases with increasing frequency

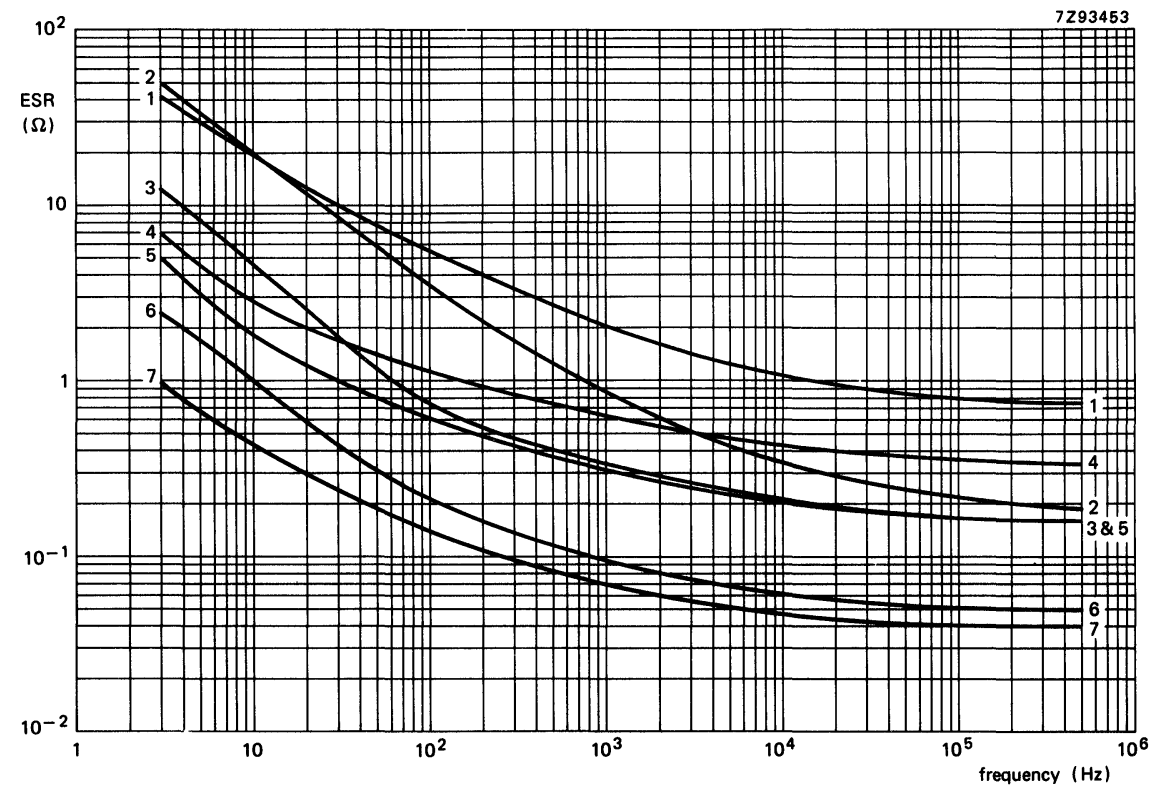

FIGURE 5 Equivalent Series Resistance as a function of frequency, at a temperature of $25^{\circ} \mathrm{C}$, for axial metalcase solid aluminium capacitors. Numbers refer to the same capacitors as in Fig. $3 \mathrm{a}$. 
faster than the resistance, so the ripple current will be the limiting factor at higher frequencies. At lower frequencies the product of the impedance value and the ripple current allowed by heat-dissipation considerations will normally exceed the tolerable ripple voltage.

Non-sinusoidal voltage loads should be split into a series of sinusoidal voltage by Fourier transforms. Because of the low impedance at high frequencies, highest currents will occur in this range. A fast sequence of charge and discharge currents should be treated in the same manner.

To find the allowable heat dissipation the next sections analyze the capacitor's construction and application on the printed-circuit board.

\section{THERMAL ANALYSIS}

\subsection{Thermal Model Calculations}

The approach mostly used in literature, ${ }^{4-6,18}$ for the capacitor's heat dissipation is based on a one-dimensional approximation of the heat flow. In that model the heat generated in the capacitor is dissipated through radiation and convection, described by the formula:

$$
\mathrm{i}^{2} \mathrm{R}=\beta \mathrm{S}\left(\mathrm{T}_{\text {surface }}-\mathrm{T}_{\text {ambient }}\right),
$$

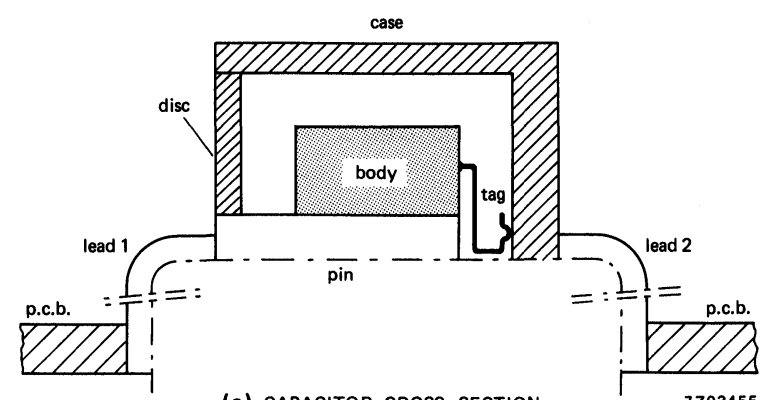

(a) CAPACITOR CROSS-SECTION

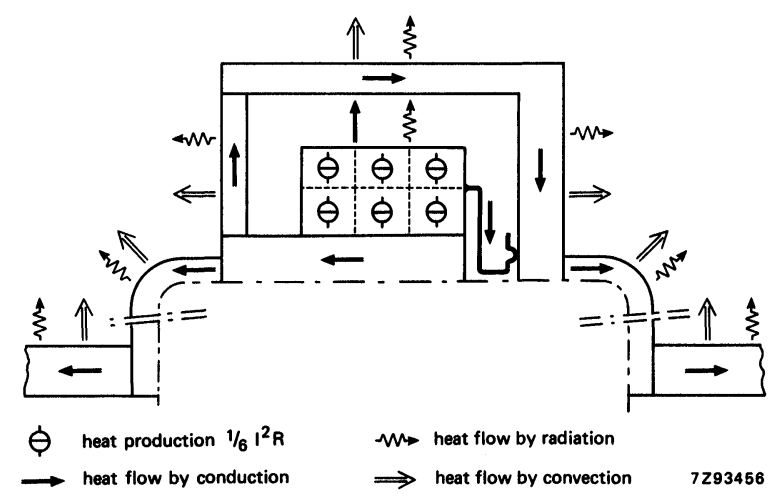

(b) SCHEME OF HEAT FLOW

FIGURE 6 Heat-flow scheme of an axial metal-case capacitor a) capacitor cross-section

b) scheme of the heat flow 
where $\mathrm{i}$ means the ripple current, $\mathrm{R}$ the resistance (the ESR), $\boldsymbol{\beta}$ the heat-transfer coefficient, $\mathrm{S}$ the outer case surface area.

The drawbacks of the model are in the first place that it leaves out of account the relation between the temperature of the surface and the capacitor core. The core temperature is, in fact, strongly dependent on the internal heat conduction as determined by the materials present, the anode and cathode connections of the capacitive body to the outside and the distance between body and surface. Obviously, the manufacturers want to take the core temperature into account. They achieve this goal by inserting for $\beta$ some apparent heat-transfer coefficient value which must be dependent on case size. For pearl-type capacitors, no data are available on this subject.

Secondly, the model neglects the important heat conduction through the connection leads and the printed-circuit board, and, for capacitors in a metal case, the conduction from top and bottom of the case to the case wall. Because of this neglect, the really allowable ripple current is grossly underestimated.

For a calculation including all thermal parameters of the capacitor the authors utilised a standard computer programme normally used for analysing electronic circuits. This can be applied by virtue of analogy principles between thermal and electronic phenomena. To that purpose, the capacitor is viewed as being constructed of separate heat resistive and heat capacitive parts. Figure 6 shows the schematic overview of an axial metal-case solid aluminium capacitor and the heat-flow scheme used for the calculations. For pearl-type capacitors a simpler model can be applied because there is no air between the various layers and almost no difference between top and side of the capacitor. The heat generation can be assumed to take place homogeneously in the capacitor cathode (manganese dioxide). The electrical analogue is shown in Figure 7.

The following thermal parameters must be known for the calculations: the various thermal conductivities; the thermal emissivity of the surface; and the heat-transfer coefficient from the component to the surroundings as a function of the position on the printed-circuit board. The determination of these paramaters is the subject of the next paragraph.
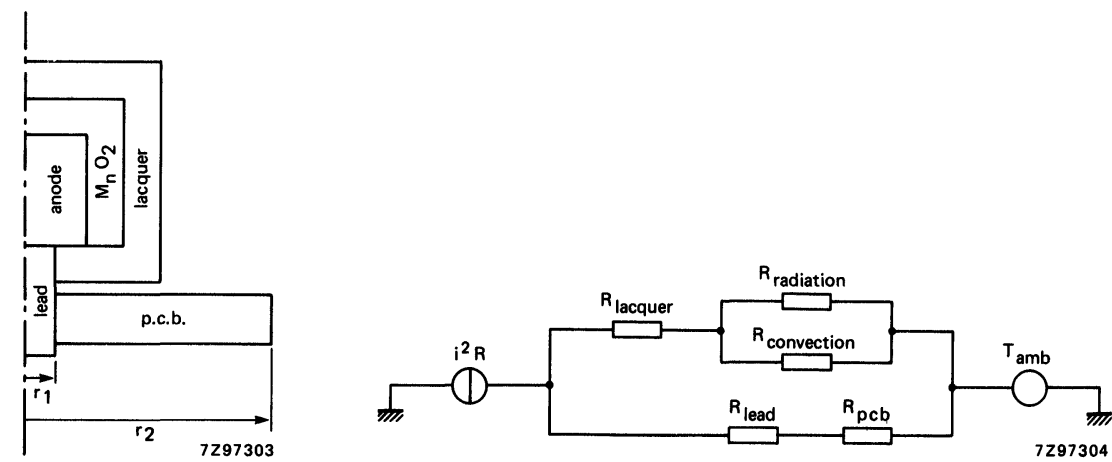

FIGURE 7 Heat-flow scheme of a radial pearl-type capacitor

a) capacitor cross-section. $r_{1}$ is the equivalent radius of one lead representing the two leads; $r_{2}$ is the radius of the part of the printed-circuit board (p.c.b.) surface without other heat-dissipating components

b) electrical equivalent for the heat flow. The generated heat $\left(i^{2} R\right)$ is dissipated through various equivalent thermal resistances $R$ to the ambient at temperature $T_{a m b}$. The term $R_{p c b}$ involves conduction into and convection and radiation from the p.c.b. 


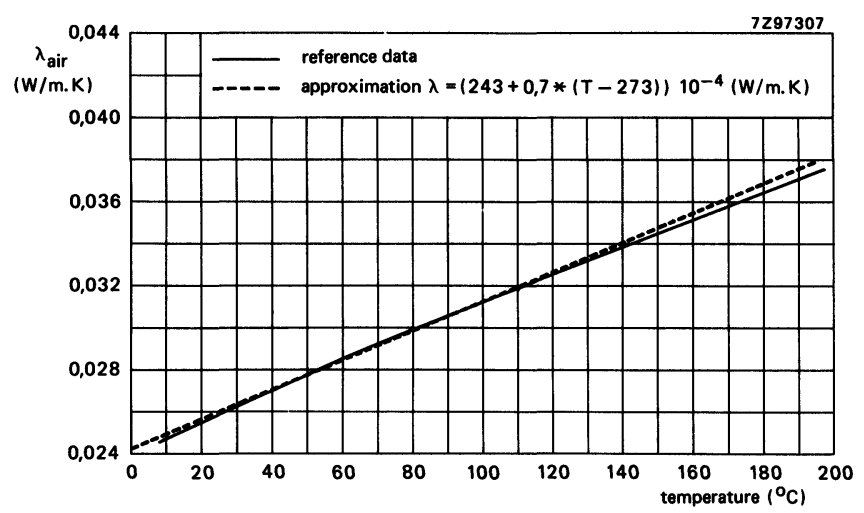

FIGURE 8 Thermal conductivity $\lambda$ of air as a function of temperature. See Ref. 19 for data.

\subsection{Thermal Parameter Values}

The thermal conductivity of air can be approximated from the various data available in literature ${ }^{19}$ in the temperature region under consideration by the linear equation (Figure 8):

$\lambda_{\text {air }}=(243+0.7 *(\mathrm{~T}-273)) 10^{-4}\left[\mathrm{~W} \mathrm{~m}^{-1} \mathrm{~K}^{-1}\right]$,

For an axial, wound foil capacitor, the heat conduction in the capacitive body itself is strongly anisotropic. It was measured by isolating certain parts of the body, determining the core temperature after immersion in boiling water, and calculating the radial and axial components of the heat conduction by the computer programme mentioned before.

The heat conduction in various possible capacitor materials is further listed in Table II. Some values are best estimates from a number of literature data; the sensitivity for this estimate will later be shown to be reasonably low.

The thermal emissivity $\varepsilon$ of the metal case has been determined by infrared thermography. The bare aluminium case appears to have $\varepsilon=0.07$; if insulated with the blue transparent sleeve presently in use the emission increases to $\varepsilon=0.83$. Because the isolation is rather thin (about $30 \mu \mathrm{m}$ ), the case itself shines through it, lowering the emission somewhat with respect to the values expected from the literature. ${ }^{20}$ The $\varepsilon$ of the orange lacquer layer on radial capacitors is estimated at 0.85 by measurements on equivalent epoxies.

TABLE II

Thermal conductivity $\lambda$ of various materials

\begin{tabular}{lc}
\hline Material & $\lambda\left(\mathrm{W} \mathrm{m}^{-1} \mathrm{~K}^{-1}\right)$ \\
\hline Aluminium & 200 \\
Aluminiumoxide, pure & 25 \\
Ceramic disc & 2.5 \\
Epoxy filling (black, silica fillers) & 0.4 \\
Polymer filling, heat conductive & 0.8 \\
Helium filling & 0.2 \\
Epoxy lacquer coating (orange, ceramic fillers) & 0.3 \\
Printed circuit board, reinforced epoxy, $2 \mathrm{~mm}$ thick, $125^{\circ} \mathrm{C}$ & 0.4 \\
Same, but having heat conduction like copper & 400
\end{tabular}


TABLE III

$\boldsymbol{\alpha}_{\mathrm{rad}}$ as a function of various parameters for metal-case capacitors

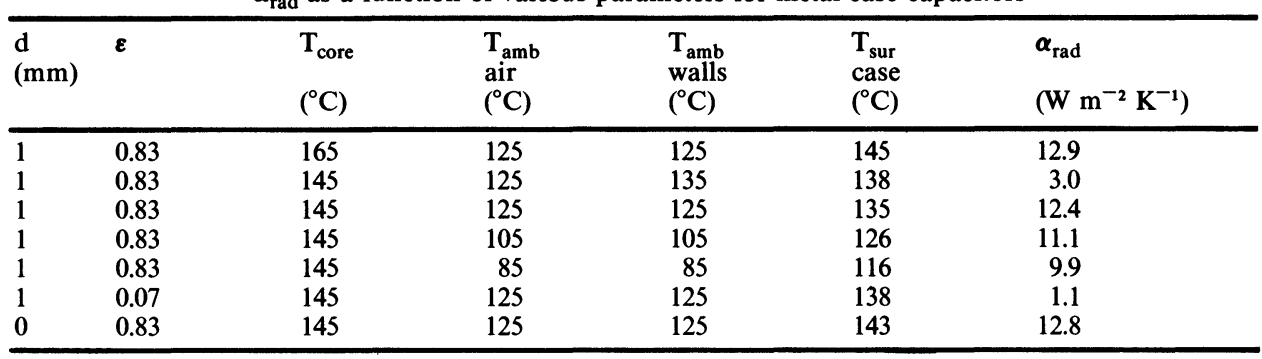

The coefficient for heat transfer by radiation, $\alpha_{\text {rad }}$, is related to $\varepsilon$ by the formula:

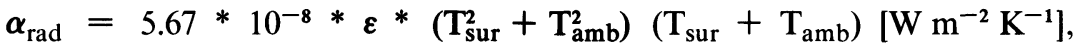

in which $T_{\text {sur }}$ and $T_{a m b}$ denote the absolute temperatures of the surface and the ambient, respectively.

Table III lists some results for $\boldsymbol{\alpha}_{\text {rad }}$ as well as actual surface temperatures, for metalcase capacitors. The capacitive body is placed at distance $d$ from the wall in the airfilled case. If the surrounding walls including the board are warmer than the ambient air, the radiation heat cannot be so easily dissipated and $\alpha_{\text {rad }}$ is much lower than represented by the previous formula.

The coefficient for heat transfer by convection $\alpha_{\text {con }}$, in still air up to $200^{\circ} \mathrm{C}$ can be calculated $^{21,22}$ as:

$\alpha_{\text {con }}=\mathrm{K}\left(\rho_{\text {alt }} / \rho_{\text {sea }}\right)^{0.5}(\Delta \mathrm{T} / \mathrm{L})^{0.25} \mathrm{~W} \mathrm{~m}^{-2} \mathrm{~K}^{-1}$,

in which denote:

$\rho_{\text {alt }}$ and $\rho_{\text {sea }}$ : the density of air at a certain altitude and at sea level, respectively (see Figure 9). K: a function relating to the properties of the ambient and the position of the capacitor. It can be approximated around $125^{\circ} \mathrm{C}$ by the formula (see Figure 10):

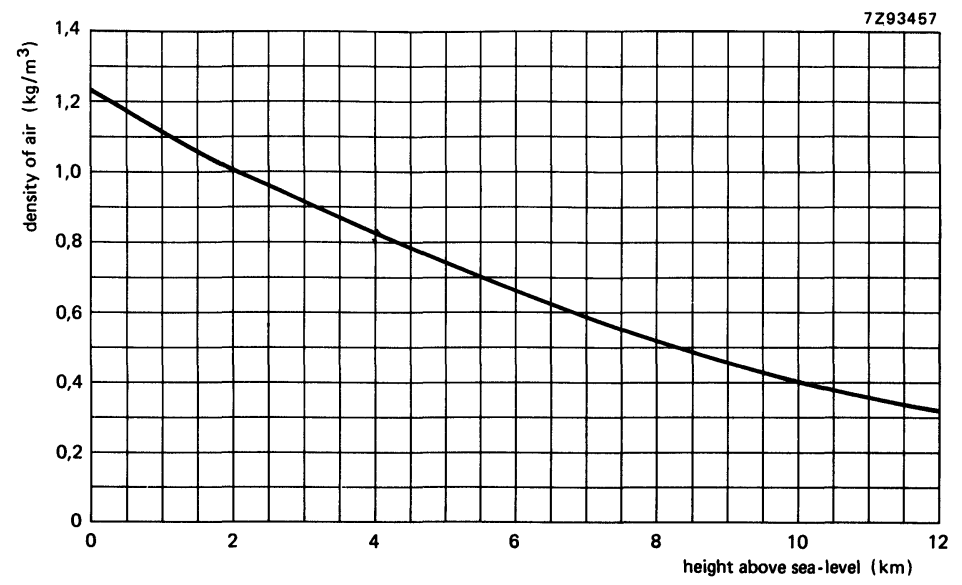

FIGURE 9 Density of air as a function of height 


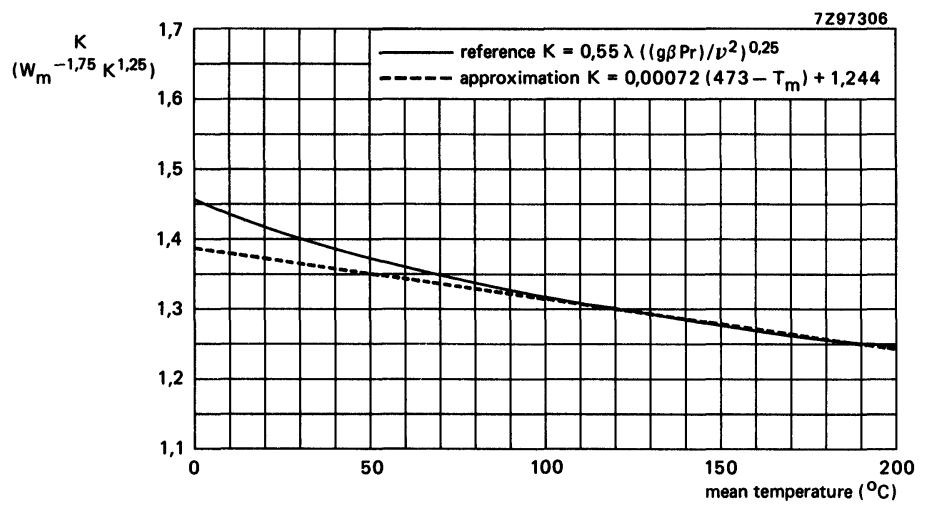

FIGURE 10 Function $\mathrm{K}$ in the equation for the convection coefficient, as a function of mean temperature $\mathrm{Tm}[\mathrm{K}], \mathrm{Tm}=\left(\mathrm{T}_{\max }+\mathrm{T}_{\mathrm{amb}}\right) / 2$. See Ref. 21,22 for data.

$$
\mathrm{K}=1.244+72 * 10^{-5}\left(473-\mathrm{T}_{\mathrm{sur}} / 2-\mathrm{T}_{\mathrm{amb}} / 2\right)\left[\mathrm{W} \mathrm{m} \mathrm{m}^{-1.75} \mathrm{~K}^{1.25}\right] \text {. }
$$

This formula applies to the situation of a capacitor mounted horizontally on a vertical printed-circuit board, which will be called the standard situation.

$\Delta \mathrm{T}: \mathrm{T}_{\text {sur }}-\mathrm{T}_{\mathrm{amb}}[\mathrm{K}]$. L: characteristic length $[\mathrm{m}]$, being for cylindrical cases either the length (in vertical position) or the diameter (in horizontal position). For the radial pearl an equivalent length of $8 \mathrm{~mm}$ can be selected regardless of position.

The calculation of $\alpha_{\text {con }}$ has been compared by actual measurements of a blackened cylindrical case, connected to a printed-circuit board. Inside the case a constant amount of power was generated, and $T_{\text {sur }}$ was measured with the help of an infraredradiation meter. After correction for $\alpha_{\text {rad }}, \alpha_{\text {con }}$ was determined as $12.7 \mathrm{~W} \mathrm{~m}^{-2} \mathrm{~K}^{-1}$, to be compared to a value of 13.1 following from the present theory for the standard situation. The worst-case situation appeared to be the horizontal mounting of the capacitor at the bottom of a horizontal printed-circuit board; this yielded a value $\alpha_{\text {con }}=10.4 \mathrm{~W} \mathrm{~m}^{-2} \mathrm{~K}^{-1}$ or about $3 / 4$ of the best-case situation. For the various other mountings $\alpha_{\text {con }}$ takes on intermediate values that are dependent on the actual capacitor size and the temperature difference with the ambient.

In the analysis of the axial cpacitors, the conduction and radiation inside the case have been taken into account, but the inside convection has been neglected because of the small dimensions involved. The surface area of the radial pearls has been determined by covering them with flexible tape and measuring the tape surface area.

\section{RESULTS AND DISCUSSION}

\subsection{Results of Thermal Analysis}

A major aim of the complete analysis was to find an easy-to-handle approximation which would still take into account all the thermal aspects neglected in the old model. Within an inaccuracy of a few percent the results can be represented by the following formula:

$\mathrm{i}^{2} \mathrm{R}=(\beta \mathrm{S}+\gamma)\left(\mathrm{T}_{\text {core }}-\mathrm{T}_{\mathrm{amb}}\right)$. 


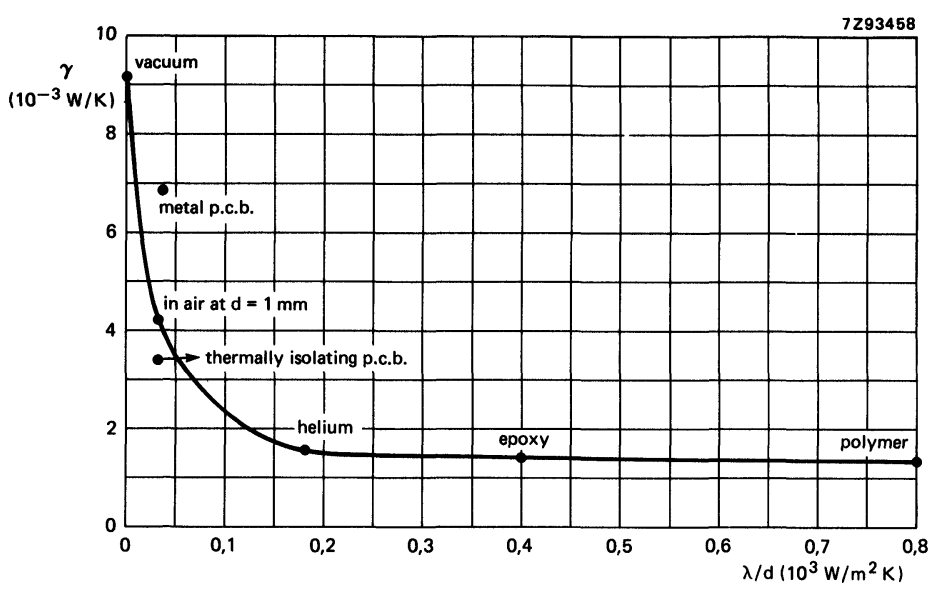

FIGURE 11 Correction factor $\gamma$ as a function of the ratio $\lambda / d$, for metal-case capacitors.

Here $\beta$ denotes the total heat-transfer coefficient; this is composed of an internal and an external part, and can be written in reciprocal form as a sum of heat resistances:

$$
1 / \beta=\mathrm{d} /(\mathrm{f} \lambda)+1 /\left(\alpha_{\mathrm{con}}+\alpha_{\mathrm{rad}}\right)
$$

in which: $d$ is the distance of the capacitive body to the inner case or lacquer surface; $\lambda$ the thermal conductivity of the medium in that distance; $f$ the ratio of the capacitivebody surface-area and the case surface-area, being unity for pearl-type capacitors.

The quantity $\gamma$ covers the heat conduction through the leads to the p.c.b. Furthermore, for metal-case capacitors it also covers the conduction from the top to the case wall and from the bottom to the leads. This single correction term appeared sufficiently accurate for the calculation, even though in fact the conduction from top to wall is parallel to the internal heat transfer from body to wall, whereas the conduction through the leads is parallel to the total external heat transfer. For metal-case capacitors, the value of $\gamma$ appeared to be dependent only on the ratio $\lambda / \mathrm{d}$ (Figure 11). The relative amount of flow through case ends and leads is almost independent of case size. For radial pearl-type capacitors, the analysis first shows that temperature differences in the capacitors can be disregarded because of the relative magnitudes of the thermal resistances (Table IV). The p.c.b. resistance is found by evaluating the Bessel functions describing the heat flux in the board. An easy approximation is valid for a radius $r_{2}>19 \mathrm{~mm}$ (see Figure 7). Then:

$\mathrm{R}_{\mathrm{pcb}}=-\left(\ln \left(\mathrm{mr}_{1}\right)\right) /(2 \pi \lambda \mathrm{t})$,

TABLE IV

Thermal resistances in a pearl-type capacitor

\begin{tabular}{lc}
\hline Resistive component & Thermal resistance $(\mathrm{K} / \mathrm{W})$ \\
\hline anode & 0.3 \\
lacquer & 10 \\
lead & 10 \\
convection + radiation & 200 \\
p.c.b. total & 530 \\
\hline
\end{tabular}


with $\mathrm{m}=(2 \alpha /(\lambda \mathrm{t}))^{0.5} ; \mathrm{r}_{1}=1.4^{*}$ single lead radius; $\alpha, \lambda, \mathrm{t}=$ heat-transfer coefficient, thermal conductivity and thickness of the p.c.b., respectively.

Here $\gamma=1 / R_{\text {pcb }}$.

The resultant formula for the ripple current is:

$\mathrm{i}=(\mathrm{Q} / \mathrm{R})^{0.5}, \quad \mathrm{Q}=(\beta \mathrm{S}+\gamma)\left(\mathrm{T}_{\text {core }}-\mathrm{T}_{\mathrm{amb}}\right)$.

TABLE V-a

The standard situation

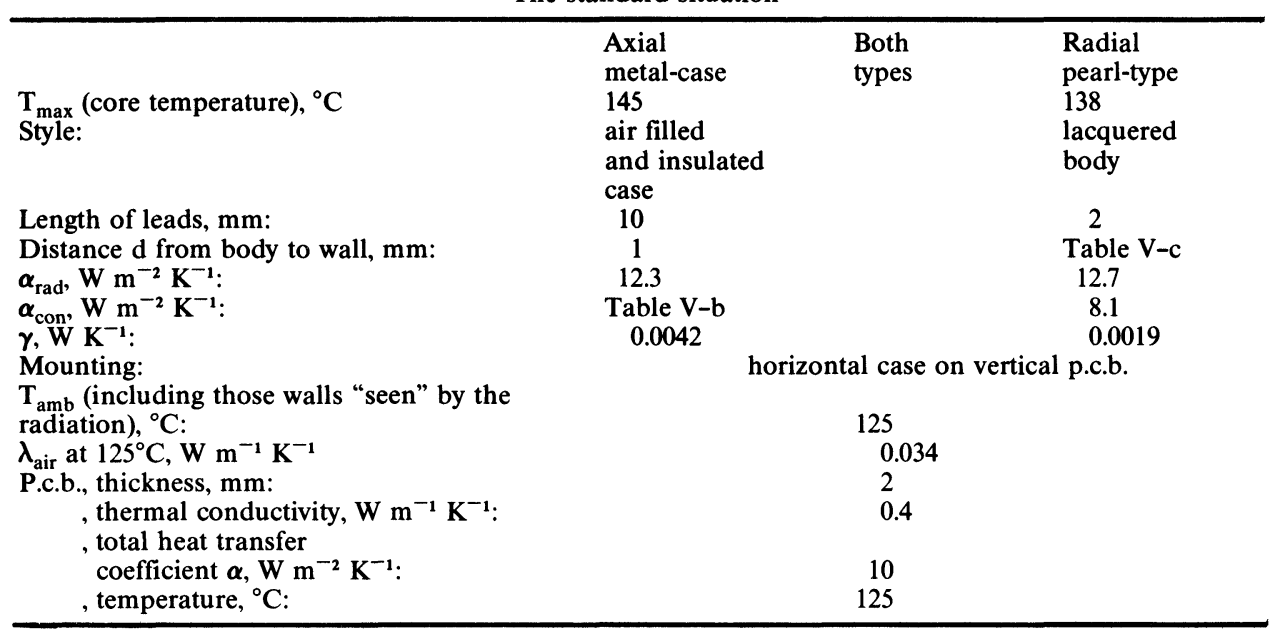

TABLE V-b

Calculation of $\mathrm{Q}$ for axial solid aluminium capacitors

\begin{tabular}{llllllll}
\hline $\begin{array}{l}\text { Case } \\
\text { size }\end{array}$ & $\begin{array}{l}\text { Diameter } \\
\text { max. } \\
(\mathrm{mm})\end{array}$ & $\begin{array}{l}\text { Length } \\
\text { max. } \\
(\mathrm{mm})\end{array}$ & $\begin{array}{l}\text { Body } \\
\text { length } \\
(\mathrm{mm})\end{array}$ & $\mathrm{f}$ & $\begin{array}{l}\boldsymbol{\alpha}_{\text {con }} \\
\left(\mathrm{W} \mathrm{m}^{-2} \mathrm{~K}^{-1}\right)\end{array}$ & $\begin{array}{l}\boldsymbol{\beta} \\
\left(\mathrm{W} \mathrm{m}^{-2} \mathrm{~K}^{-1}\right)\end{array}$ & $\begin{array}{l}\mathrm{Q} \\
(\mathrm{W})\end{array}$ \\
\hline 1 & 6.7 & 15.3 & 5 & 0.26 & 8.6 & 6.2 & 0.13 \\
2 & 7.6 & 20.4 & 8 & 0.33 & 8.3 & 7.2 & 0.16 \\
4 & 9.3 & 23.3 & 12 & 0.43 & 7.9 & 8.5 & 0.21 \\
5 & 10.3 & 32 & 15 & 0.39 & 7.5 & 8.0 & 0.26 \\
6 & 12.9 & 32 & 15 & 0.38 & 6.9 & 7.7 & 0.32 \\
$6 \mathrm{~S}$ & 12.9 & 32 & 20 & 0.50 & 7.1 & 9.2 & 0.36 \\
\hline
\end{tabular}

TABLE V-c

Calculation of $\mathrm{Q}$ for radial solid aluminium capacitors

\begin{tabular}{|c|c|c|c|c|}
\hline Size & $\begin{array}{l}\mathrm{S} \\
\left(\mathrm{mm}^{2}\right)\end{array}$ & $\begin{array}{l}\mathrm{d} \\
(\mathrm{mm})\end{array}$ & $\begin{array}{l}\beta \\
\left(W m^{-2} K^{-1}\right)\end{array}$ & $\begin{array}{l}Q \\
(W)\end{array}$ \\
\hline $\begin{array}{l}1 \\
2 \\
3 \\
4\end{array}$ & $\begin{array}{l}165 \\
204 \\
247 \\
322\end{array}$ & $\begin{array}{l}0.9 \\
1.0 \\
1.0 \\
1.2\end{array}$ & $\begin{array}{l}19.6 \\
19.5 \\
19.5 \\
19.2\end{array}$ & $\begin{array}{l}0.068 \\
0.077 \\
0.087 \\
0.105\end{array}$ \\
\hline
\end{tabular}




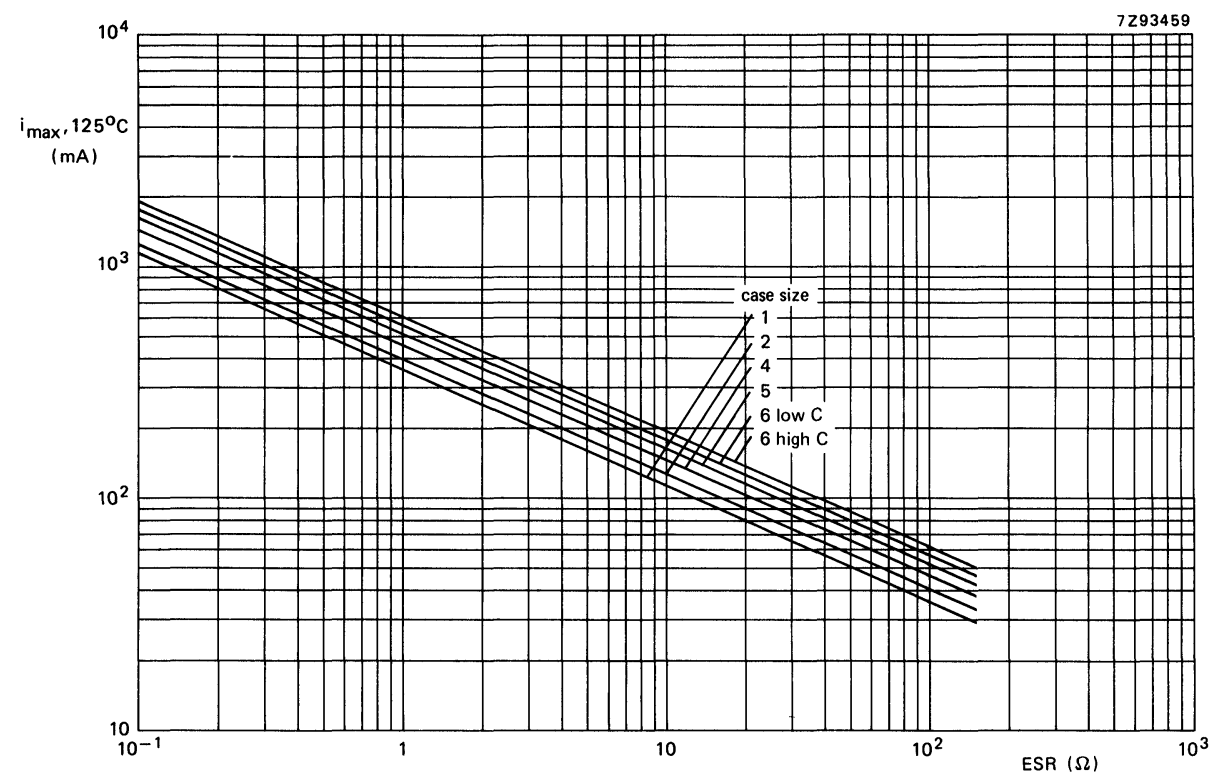

FIGURE 12 a - Max. ripple current at $125^{\circ} \mathrm{C}$ as a function of ESR, in the standard situation, for axial solid aluminum capacitors.

The dependence of $\mathrm{R}$ on temperature has been neglected in first order, because in an actual application the component may have a cold start before reaching the equilibrium temperature.

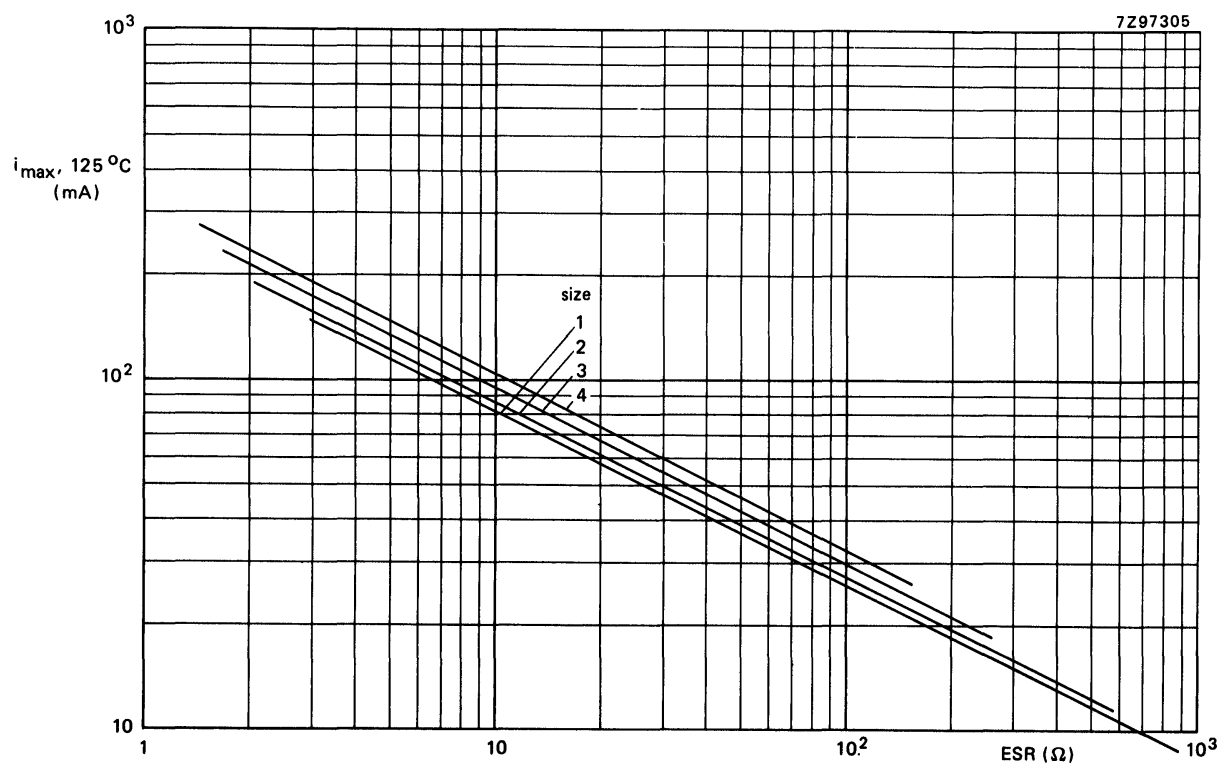

FIGURE 12 b - Same, for radial solid aluminium capacitors. 
Table V-a describes the standard situation. Tables V-b and V-c list the actual parameter values and the results for $Q$ calculated assuming the standard situation, for standard axial and radial solid aluminium capacitor ranges, respectively. From Figures 12a and $\mathrm{b}$ the allowed maximum ripple-current value at $125^{\circ} \mathrm{C}$ ambient temperature can be read as a function of the capacitor's resistance. For a selection of non-standard situations described in Table VI-a, Tables VI-b and VI-c list the appropriate ripplecurrent multipliers, giving an impression of the sensitivity of the different capacitor sizes to each situation.

The following remarks apply to these situations:

1) Most factors can be multiplied with one another, provided they are not based on interdependent situations (e.g. like those for epoxy filling and for $\mathrm{d}=0$, because the filling is a function of $d$ ).

2) The position of the capacitor and the printed-circuit board (code $h$ in Table VI) hardly matters as long as the surrounding walls including the board itself are kept at $125^{\circ} \mathrm{C}$. If the surrounding as seen by the radiation is warmer than the air temperature of $125^{\circ} \mathrm{C}$, the radiation heat cannot so easily dissipate (code $\mathrm{f}$ ).

3) The neglect of heat flow through ends and leads (which is conventional practice) is seen to cause a gross underestimation especially for the smaller component sizes (code $\mathrm{m}$ ). The p.c.b. has a large influence (codes $\mathrm{j}$ and $\mathrm{l}$ ).

4) The influence of other core and ambient temperatures is mainly proportional to the value of $\Delta \mathrm{T}$. Calculations up to $220^{\circ} \mathrm{C}$ core temperatures show that the ripple current can be up to $10 \%$ larger than that calculated assuming just the $\Delta T$-dependence while keeping other parameter values equal to those valid at $145^{\circ} \mathrm{C}$ core temperature.

5) The influence of forced convection cooling is demonstrated for 2 situations (codes $t$ and $u$ ), representing typical applications where electronic equipment is cooled by small and large fans, respectively. This effect becomes increasingly important for larger capacitor sizes.

\subsection{Ripple Specification for Solid Aluminium Capacitors}

Solid aluminium capacitors have had a conservative specification with respect to their intrinsic temperature limit. Now it appears that their heat dissipation potential has also been underestimated. To demonstrate the validity of the present calculations in practice, a number of samples in various case sizes and voltage values are put under test at $100 \mathrm{~Hz}$ and $125^{\circ} \mathrm{C}$. The ripple current load has been increased two- to threefold with respect to specification, to comply with the low actual specimen's resistance. No bias (d.c.) voltage is applied. The results after $2000 \mathrm{~h}$ show no significant parameter change due to this load. Apparently the present calculations do not yet indicate the physical limits of these capacitors.

The ripple current multipliers for different temperatures and frequencies are shown in Figure 13. The frequency multiplier is derived from the typical dependence of ESR on irequency. In the low frequency region, below about $50 \mathrm{~Hz}$, the multipliers are conservative because no correction to the ESR has been made as discussed in section 2.2. for the parallel resistance of the dielectric. The major influence on the temperature dependency is exercised by the value of $\Delta T$. The temperature dependence would be influenced to a small extent by the dependence of the ESR on temperature, but this effect has been neglected. The dependencies on temperature and frequency are assumed to be mutually independent. This is in fact a worst-case approximation because the decrease of ESR with increasing frequency at higher temperatures is faster than at lower temperatures (see Figure 14).

Finally, the limitations opposed by the ripple voltage have to be observed even more, 
TABLE VI-a

List of various conditions of application

\begin{tabular}{|c|c|}
\hline Code & Description \\
\hline a. & Metal case not isolated, $\varepsilon=0.07$ \\
\hline b. & Max. core temperaure $165^{\circ} \mathrm{C}$ \\
\hline c. & Max. core temperature $145^{\circ} \mathrm{C}$ \\
\hline d. & $\mathrm{T}_{\mathrm{amb}} 105^{\circ} \mathrm{C}$ (walls included) \\
\hline e. & $\mathrm{T}_{\mathrm{amb}} 85^{\circ} \mathrm{C}$ (walls included) \\
\hline f. & $\mathrm{T}_{\text {air }}=125^{\circ} \mathrm{C}, \mathrm{T}_{\text {walls }}=135^{\circ} \mathrm{C}$ \\
\hline g. & Capacitor at $10 \mathrm{~km}$ height \\
\hline h. & Worst-case mounting, $\alpha_{\text {con }}$ times 0.75 \\
\hline i. & P.c.b. having copper-like thermal conducton $\left(\lambda=400 \mathrm{~W} \mathrm{~m}^{-1} \mathrm{~K}^{-1}\right)$ \\
\hline j. & P.c.b. having $\lambda=200 \mathrm{~W} \mathrm{~m}^{-1} \mathrm{~K}^{-1}$ \\
\hline k. & P.c.b. having $\lambda=0.2 \mathrm{~W} \mathrm{~m}^{-1} \mathrm{~K}^{-1}$ \\
\hline 1. & No heat conduction along p.c.b. \\
\hline m. & No heat conduction along leads or case ends \\
\hline o. & Metal case filled with helium, $\lambda=0.2 \mathrm{~W} \mathrm{~m}^{-1} \mathrm{~K}^{-1}$ \\
\hline p. & Metal case filled with epoxy, $\lambda=0.4 \mathrm{~W} \mathrm{~m}^{-1} \mathrm{~K}^{-1}$ \\
\hline q. & Metal case filled with heat-conductive polymer, $\lambda=0.8 \mathrm{~W} \mathrm{~m}^{-1} \mathrm{~K}^{-1}$ \\
\hline r. & Capacitive body close to metal case wall, $d=0$ \\
\hline s. & Pure aluminium-oxide disc, $\lambda=25 \mathrm{~W} \mathrm{~m}^{-1} \mathrm{~K}^{-1}$ \\
\hline t. & Typical forced convection, turbulent flow, $\alpha_{\text {con }}=20 \mathrm{~W} \mathrm{~m}^{-2} \mathrm{~K}^{-1}$ \\
\hline u. & Heavily forced convection, turbulent flow, $\alpha_{\text {con }}=50 \mathrm{~W} \mathrm{~m}^{-2} \mathrm{~K}^{-1}$ \\
\hline
\end{tabular}

TABLE VI-b

Multipliers of ripple current for axial metal case capacitors at the conditions of Table VI-a

\begin{tabular}{llllllllll}
\hline Conditions & $\mathrm{a}$ & $\mathrm{b}$ & $\mathrm{d}$ & $\mathrm{e}$ & $\mathrm{f}$ & $\mathrm{g}$ & $\mathrm{h}$ & $\mathrm{i}$ & $\mathrm{l}$ \\
\hline Case size: & & & & & & & & & \\
1 & 0.88 & 1.45 & 1.42 & 1.74 & 0.90 & 0.94 & 0.98 & 1.19 & 0.90 \\
2 & 0.86 & 1.45 & 1.42 & 1.74 & 0.89 & 0.94 & 0.97 & 1.15 & 0.92 \\
4 & 0.84 & 1.45 & 1.42 & 1.74 & 0.88 & 0.94 & 0.97 & 1.12 & 0.94 \\
5 & 0.84 & 1.45 & 1.42 & 1.73 & 0.87 & 0.95 & 0.96 & 1.09 & 0.96 \\
6 & 0.84 & 1.46 & 1.42 & 1.73 & 0.86 & 0.95 & 0.96 & 1.08 & 0.97 \\
$6 \mathrm{~S}$ & 0.83 & 1.46 & 1.41 & 1.73 & 0.86 & 0.95 & 0.96 & 1.08 & 0.96 \\
& $\mathrm{~m}$ & $\mathrm{o}$ & $\mathrm{p}$ & $\mathrm{q}$ & $\mathrm{r}$ & $\mathrm{s}$ & $\mathrm{t}$ & $\mathrm{u}$ & \\
& & & & & & & & & \\
1 & 0.56 & 1.10 & 1.16 & 1.20 & 1.25 & 1.05 & 1.02 & 1.04 & \\
2 & 0.71 & 1.14 & 1.20 & 1.23 & 1.26 & 1.05 & 1.05 & 1.09 & \\
4 & 0.77 & 1.17 & 1.23 & 1.26 & 1.29 & 1.06 & 1.07 & 1.09 & \\
5 & 0.79 & 1.20 & 1.26 & 1.30 & 1.34 & 1.06 & 1.08 & 1.14 & \\
6 & 0.83 & 1.23 & 1.30 & 1.33 & 1.36 & 1.06 & 1.06 & 1.12 & \\
$6 \mathrm{~S}$ & 0.86 & 1.20 & 1.26 & 1.28 & 1.32 & 1.06 & 1.07 & 1.16 & \\
\hline
\end{tabular}

TABLE VI-c

Multipliers of ripple current for radial pearl capacitors at the conditions of Table VI-a

\begin{tabular}{llllllllllll}
\hline Conditions: & $\mathrm{b}$ & $\mathrm{c}$ & $\mathrm{d}$ & $\mathrm{e}$ & $\mathrm{f}$ & $\mathrm{g}$ & $\mathrm{h}$ & $\mathrm{j}^{\dagger}$ & $\mathrm{k}$ & 1 \\
\hline Capacitor & & & & & & & & & & & \\
Size & & & & & & & & & & \\
1 & 1.85 & 1.26 & 1.62 & 2.06 & 0.70 & 0.94 & 0.97 & 2.91 & 0.92 & 0.79 \\
2 & 1.85 & 1.26 & 1.62 & 2.06 & 0.70 & 0.93 & 0.97 & 2.74 & 0.93 & 0.82 \\
3 & 1.86 & 1.26 & 1.62 & 2.07 & 0.70 & 0.93 & 0.97 & 2.59 & 0.94 & 0.84 \\
4 & 1.87 & 1.27 & 1.62 & 2.07 & 0.71 & 0.93 & 0.96 & 2.39 & 0.95 & 0.87 \\
\hline
\end{tabular}

${ }^{\dagger}$ Note: computed assuming a finite free heat-transfer area having a radius of $30 \mathrm{~mm}$, resulting in $\gamma=0.041 \mathrm{WK}^{-1}$ 


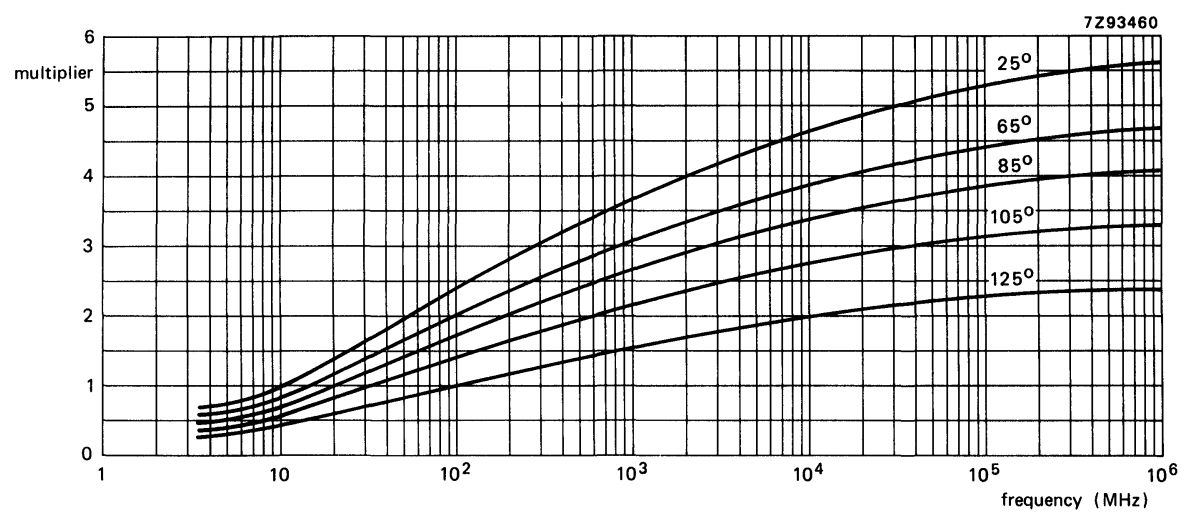

FIGURE 13 Ripple-current multiplier as a function of frequency and temperature for solid aluminium capacitors.

because the ripple current can now be upgraded. Figure 15 shows a typical example of the respective boundaries. For this example the ripple voltage is limiting up to $120 \mathrm{~Hz}$ at room temperature, whereas the ripple current is limiting from $240 \mathrm{~Hz}$ onwards. In the intermediate frequency range both factors are limiting: voltage in case the actual capacitor impedance is near its maximum value, and current in case the impedance is near its minimum value. At higher temperatures the impedance decreases and the

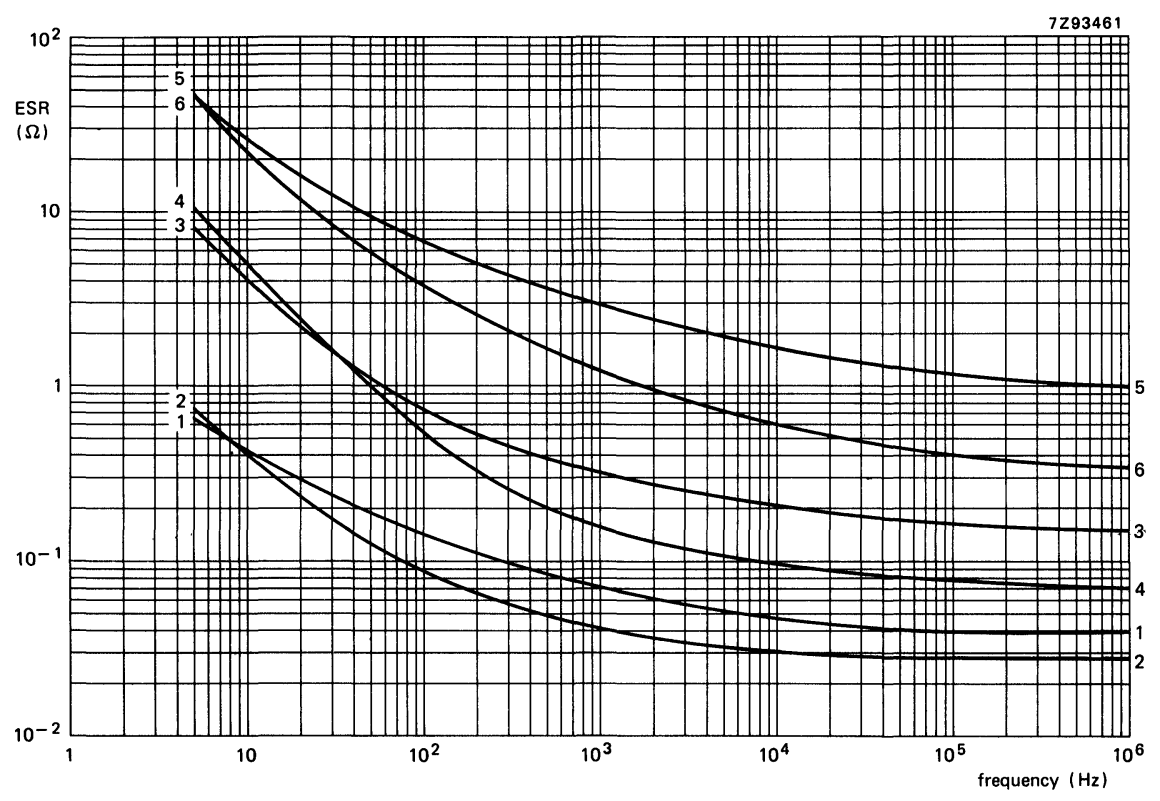

FIGURE 14 ESR as a function of frequency at 25 and $125^{\circ} \mathrm{C}$ for axial solid aluminium capacitors. Curves 1 and $2=1000 \mu \mathrm{F}-6,3 \mathrm{~V}$ at $25^{\circ} \mathrm{C}$ and $125^{\circ} \mathrm{C}$ respectively Curves 3 and $4=100 \mu \mathrm{F}-10 \mathrm{~V}$ at $25^{\circ} \mathrm{C}$ and $125^{\circ} \mathrm{C}$ respectively Curves 5 and $6=10 \mu \mathrm{F}-16 \mathrm{~V}$ at $25^{\circ} \mathrm{C}$ and $125^{\circ}$ respectively. 


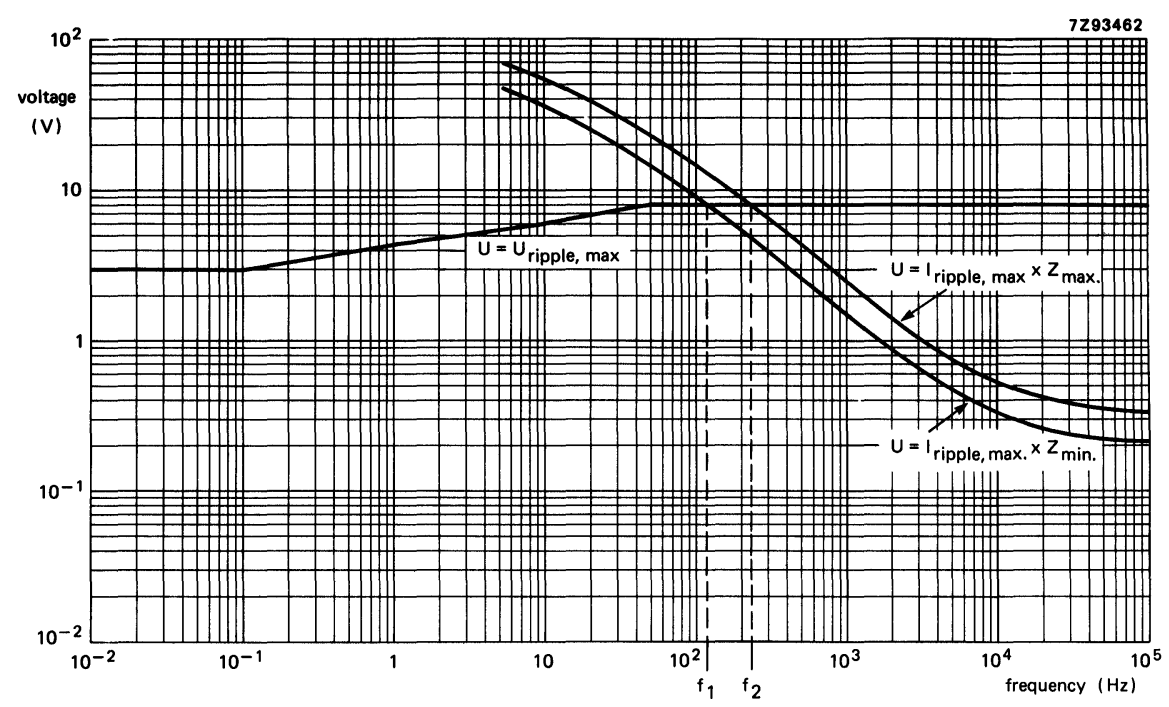

FIGURE 15 Interference of max ripple voltage $U$ and max. ripple current I. Example: $100 \mu \mathrm{F}-10 \mathrm{~V}$ axial solid aluminium capacitor at $25^{\circ} \mathrm{C}$.

$\mathrm{f}<\mathrm{f}_{\mathbf{1}}=$ limitation by $\mathrm{U}_{\text {ripple }}$, max.

$\mathrm{f}_{1}<\mathrm{f}<\mathrm{f}_{2}=$ limitation by $I_{\text {ripple }}$, max. and $U_{\text {ripple }}$, max.

$\mathrm{f}>\mathrm{f}_{2}=$ limitation by $I_{\text {ripple, }}$ max.

cross-over shifts to lower frequencies. The larger-capacitance types have a lower impedance value than the smaller types, so for them the cross-over also shifts to lower frequencies. Obviously, one can translate the current limitation into a voltage limitation by using the capacitor's impedance value. This complicates the basic physical limitations with a factor which is only partly involved, viz. as far as the impedance is determined by its resistive component.

A conservative assumption still unchanged is the dependency of voltage on frequency and temperature. This is particularly important at lower frequencies, where ripple voltage limits the current below the values calculated above. Because most standards and specifications involve a $100 \mathrm{~Hz}$ basic specification, the voltage influence cannot be neglected. Collection of more data is necessary to improve the physical basis.

\section{CONCLUSIONS}

- The use of a thermal model neglecting the heat flow through the capacitor ends and the leads, grossly underestimates the allowable ripple current. A single correction term in the formula is sufficient to cover this infuence.

- A set of multipliers is presented to include various possible capacitor features as well as applicational circumstances.

- The present thermal approach is valid for any capacitor type. At a given ESR the capacitor's temperature and voltage performance are the basic physical properties determining the ripple-current performance. Because of this, solid aluminium capacitors will take more advantage of the enlarged thermal limits. 


\section{ACKNOWLEDGEMENTS}

The authors gratefully acknowledge the efforts by Mr. A. Dekker and Mr. A. Stijf in improving and measuring the capacitors performance and the fruitful discussions with Dr. C. Crevecoeur and Mr H. van der Ploeg.

\section{REFERENCES}

1. G. Hörmansdörfer and E. Nolte, "Borehole geophone for ultra deep wells". (in German) Research Note T84-230, (Bundesministerium für Forschung und Technologie, Eggenstein - Leopoldshafen, 1984).

2. E.H.L.J. Dekker and H. Schmickl, "Advances in solid-aluminium electrolytic capacitor technology". Electron. Comp. Appl. 3, 206-209 (1981).

3. E.H.L.J. Dekker and P.S. Friedrich, "Small electrolytic capacitors compared", Electron. Comp. Appl. 4, 158-162 (1982).

4. L.L. Macomber, "Compute thermal resistance - the key to computer-grade ripple". Electron. Design 12, 80-83 (1979).

5. G. Helwig and O. Baur, "Determination of the heat-transfer coefficient for power electrolytic capacitors" (in German). Elektronik-Anzeiger 12, 15-23 (1980).

6. R. Webinger, "Enhanced power-handling capacity of modern aluminium electrolytic capacitors subjected to a superimposed ripple-current". (in German). Bauteile Rep. 16, 201-204 (1978).

7. J. Both, "Solid-Aluminium Technology" (in German). Markt Techn. 25, 55-58 (1982).

8. J. Hasegawa and K. Morimoto, "Characteristics and failure analysis of solid tantalum capacitors". NEC Res. Developm. 50, 79-94 (1978).

9. B. Goudswaard and F.J.J. Driesens, "Failure mechanism of solid tantalum capacitors", Electrocomp. Sci. Technol. 3, 171-179 (1976).

10. J.D. Moynihan and A.M. Holladay, "Effectiveness of surge current screening of solid tantalum capacitors". 3rd Capacitor and Resistor Technology Symposium, (Components Technology Institute, Huntsville, 1983) pp. 53-60

11. G.E. Getson, "Solid tantalum capacitor surge current testing". 4th Capacitor and Resistor Technology Symposium, (Components Technology Institute, Huntsville, 1984) pp. 58-63

12. J. Brettle and N.F. Jackson, "Failure mechanisms in solid electrolytic capacitors". Electrocomp. Sci. Technol. 3, 233-246 (1977).

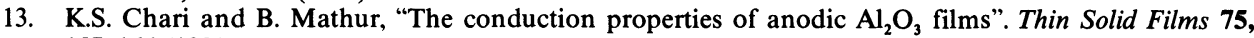
157-166 (1981).

14. H.J. de Wit, C. Wijenberg and C. Crevecoeur, "Impedance measurements during anodization of aluminium". J. Electrochem. Soc. 126, 779-785 (1979).

15. E.H.L.J. Dekker, D. Fidder and H. Schmickl, "Small electrolytic capacitors - the argument for solid aluminium types". Electron. Eng. 54, 75-86 (1982).

16. F.G. Hayatee, "The equivalent series resistance in electrolytic capacitors", Electrocomp. Sci. Technol. 2, 67-72 (1975).

17. L. Cathey and K.A. Joyner, "Investigation of the dissipation process in electrolytic capacitors". Electrocomp. Sci. Technol. 6, 49-53 (1980).

18. F.G. Hayatee, "Heat dissipation and ripple current rating in electrolytic capacitors". Electrocomp. Sci. Technol. 2, 109-114 (1975).

19. Y.S. Touloukian, "Thermophysical properties of matter". (IFI/Plenum, New York, 1970) Vol 3, p. 512.

20. Y.S. Touloukian, "Thermophysical properties of matter". (IFI/Plenum, New York, 1970) Vol 8.

21. VDI Wärmeatlas (VDI-Verlag, Düsseldorf, 1977). Vol. Fa, p. 1.

22. H. Gröber, S. Erk and U. Grigull, Die Grundgesetze der Wärmeübertragung, (Springer, Berlin, 1981) p. 282. 

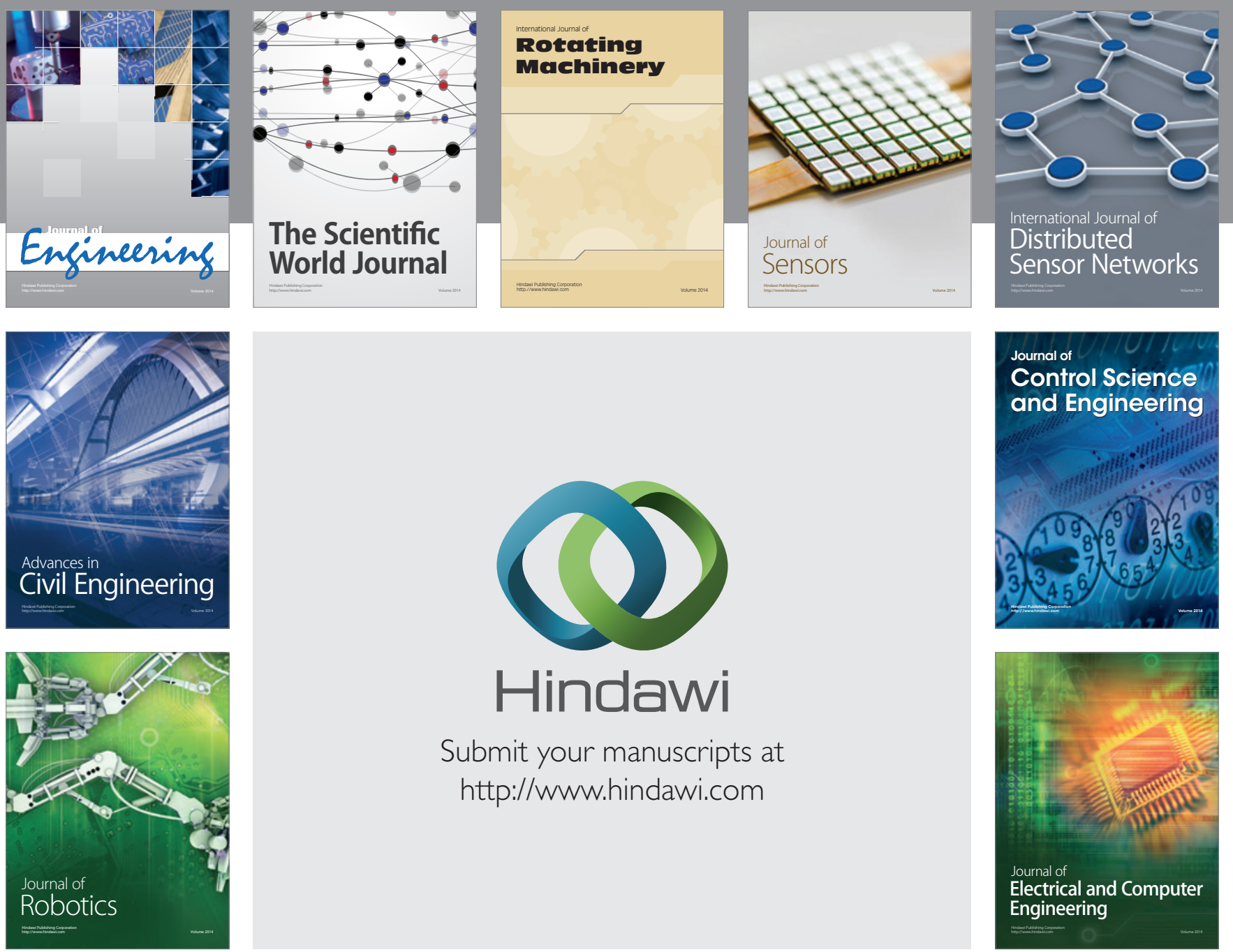

Submit your manuscripts at

http://www.hindawi.com
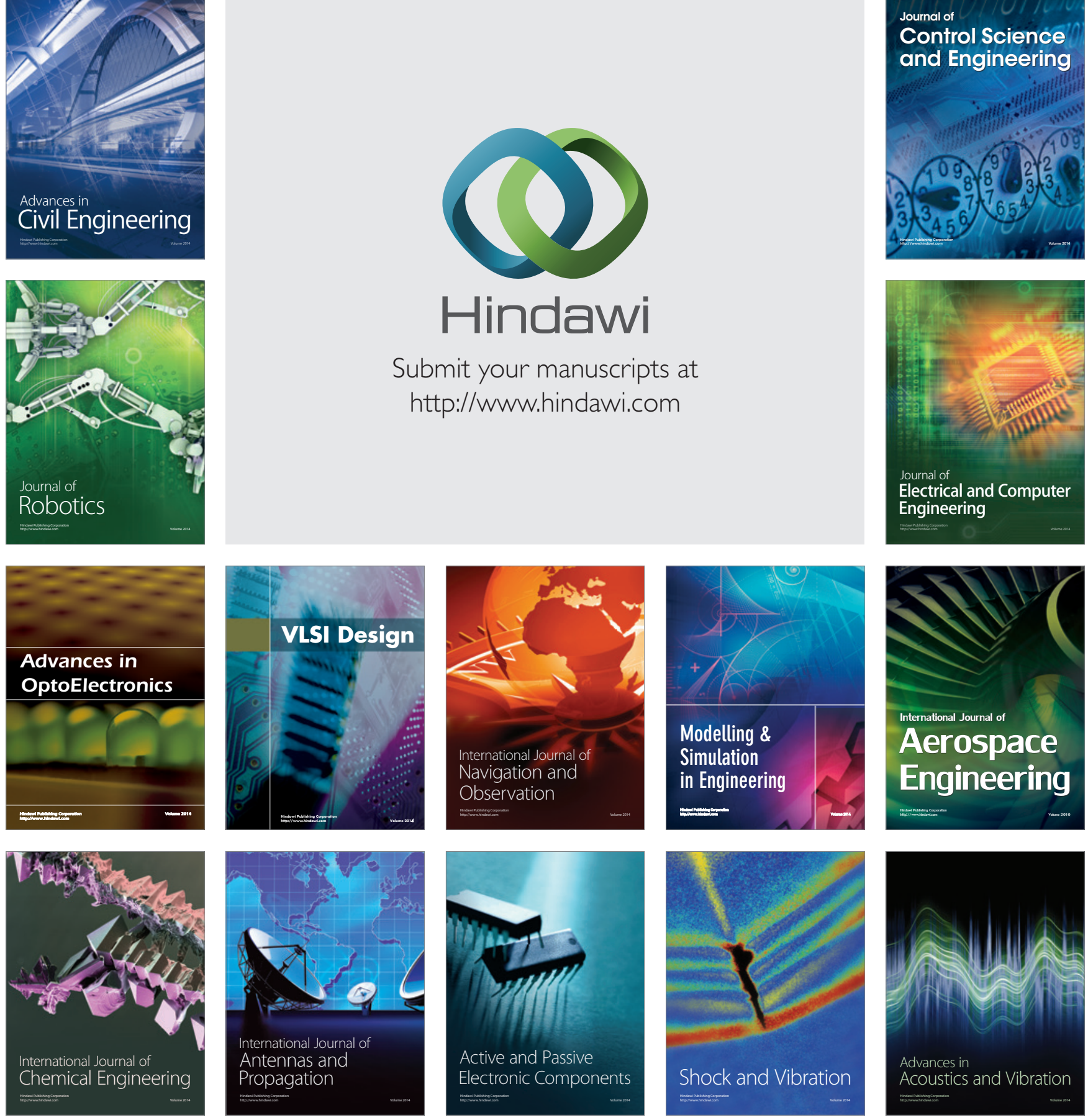